\title{
Importance of Timing of Magnesium Administration in the Isolated Ischemic-Reperfused Rat Heart: Role of $K_{\mathrm{ATP}}$ Channels
}

\author{
M. BAZARGAN ${ }^{1}$, M. FAGHIHI ${ }^{1}$, M. CHITSAZ ${ }^{2}$ \\ ${ }^{1}$ Department of Physiology, Faculty of Medicine, University of Tehran, Tehran, ${ }^{2}$ Faculty of \\ Medicine, Shahed University, Tehran, Iran
}

Received March 5, 2007

Accepted September 27, 2007

On-line November 30, 2007

\section{Summary}

There is a growing interest for the beneficial effect of magnesium (Mg) in cardiovascular disorders. A number of cardiovascular disorders including myocardial infarction, arrhythmias and congestive heart failure have been associated with low extracellular or intracellular concentrations of $\mathrm{Mg}$. The efficiency of the preconditioning effect of $\mathrm{Mg}$ on cardiac function and infarct size in the globally ischemic-reperfused isolated rat heart was studied together with the role of ATP-sensitive potassium $\left(\mathrm{K}_{\mathrm{ATP}}\right)$ channels in protection induced by $\mathrm{Mg}$. Rat hearts were Langendorff perfused, subjected to $30 \mathrm{~min}$ of global ischemia and $90 \mathrm{~min}$ of reperfusion, including treatment groups which focused on different times of $\mathrm{Mg}(8 \mathrm{mmol} / \mathrm{l})$ use. Infarct size was measured by triphenyltetrazolium chloride (TTC) method. The left ventricular function was assessed by left ventricular developed pressure (LVDP), heart rate (HR) and coronary flow (CF). The administration of $\mathrm{Mg}$ before ischemia had an anti-infarct effect in rat hearts and improved cardiac function. The protective effects of magnesium was abolished by the blocking of $\mathrm{K}_{\mathrm{ATP}}$ channels and suggests that K-ATP channel has an important role in the heart protection effect of $\mathrm{Mg}$ as a preconditioning agent.

\section{Key words}

$\mathrm{K}_{\text {ATP }}$ channel - Preconditioning - Reperfusion - Magnesium • Diazoxide • Glibenclamide

\section{Corresponding author}

M. Bazargan, Department of Physiology, Faculty of Medicine, Tehran Medical Sciences University, Tehran, Iran. E-mail: Maryam.Bazargan@postgrads.unisa.edu.au

\section{Introduction}

A considerable number of experimental, epidemiological and clinical studies point to an important role of magnesium in the etiology of cardiovascular pathology. A number of cardiovascular disorders including myocardial infarction, arrhythmias, sudden cardiac death, ventricular complications in diabetes mellitus and congestive heart failure have been associated with low extracellular or intracellular concentrations of $\mathrm{Mg}$ or abnormalities in $\mathrm{Mg}$ metabolism (Fox et al. 1997, Schechter et al. 2000, Chakraborti et al. 2002, Fuentes et al. 2006).

Magnesium plays an essential role in a wide range of fundamental cellular reactions in patients with ischemic heart disease. It also controls cardiac excitability, neuromuscular transmission, vasomotor tone, and blood pressure, among other functions such as maintaining myocardial electrical stability in hemodialysis patients (Yokoyama and Kawamura 2005).

There is growing interest for beneficial effect of $\mathrm{Mg}$ on the cardiovascular disorders. From an epidemiological view point, chronic $\mathrm{Mg}$ deficiency due to its low intake could play a role in the onset of ischemic heart disease, vasospasm of coronary artery and exacerbate several coronary risk factors such as hypertension, diabetes mellitus, and mental stress. Blood concentration of $\mathrm{Mg}$ in patients with ischemic heart disease, especially acute coronary syndrome, was lower than that of healthy subjects and may result in serious cardiac ischemia (Ueshima 2005).

The clinical application of $\mathrm{Mg}$ therapy in acute myocardial infarction still remains controversial (Stuhlinger et al. 2002). According to the large-scale 
clinical trials, the efficacy of $\mathrm{Mg}$ administrated to patients with acute myocardial infarction has not been established, but supplementary $\mathrm{Mg}$ may keep adequate blood $\mathrm{Mg}$ levels and protect from cardiac injury or cardiac ischemia (Ueshima 2005).

Despite these conflicting results, several experimental myocardial infarction studies have suggested that $\mathrm{Mg}$ treatment is potentially effective in reducing infarct size in different animal species. Furthermore, some studies have suggested that $\mathrm{Mg}$ supplementation should be considered as a preventive measure in atherosclerosis and ischemic heart disease and the intake of magnesium may have a modest inverse association with the risk of congestive heart diseases among men (Al-Delaimy et al. 2004, Ueshima 2005). Thus the optimum time and efficacy for administering $\mathrm{Mg}$ remain to be determined. The better understanding of mechanisms by which $\mathrm{Mg}$ acts as a cardioprotective agent will provide the ability of choosing the correct time for reasonable use of $\mathrm{Mg}$.

The aim of this study was to compare protective effects of magnesium as a pharmacological preconditioning agent (Mg-Pre) and $\mathrm{Mg}$ administration during reperfusion (Mg-Rep) in the isolated globally ischemic-reperfused rat heart. $\mathrm{Mg}$ was administered shortly before ischemia for $5 \mathrm{~min}$ to see its preconditioning effect and during reperfusion time for $90 \mathrm{~min}$ to see its protection after ischemia. We also assessed whether heart protection against ischemiareperfusion injury induced by $\mathrm{Mg}$ is mediated by $\mathrm{K}_{\mathrm{ATP}}$ channels or not. To accomplish these goals, a $\mathrm{K}_{\mathrm{ATP}}$ channel opener, diazoxide, and a channel blocker, glibenclamide, was used (Miura and Miki 2003). It has been suggested that classic sulfonylureas such as tolbutamide and glibenclamide (also known as glyburide) may have adverse effects on the cardiovascular system mainly because they also close mitochondrial $\mathrm{K}_{\mathrm{ATP}}$ channels, which play a central role in ischemic preconditioning (IPC) protection (Li et al. 2000). Glibenclamide has been widely assumed to block both sarcolemmal and mitochondrial $\mathrm{K}_{\mathrm{ATP}}$ channels, while Garlid et al. (1997) reported that diazoxide opened mitochondrial $\mathrm{K}_{\mathrm{ATP}}$ channels with a $\mathrm{k}_{1 / 2}$ of 0.8 $\mathrm{mmol} / \mathrm{l}$ and $800 \mathrm{mmol} / \mathrm{l}$ was required to open the sarcolemmal $\mathrm{K}_{\mathrm{ATP}}$ channels.

In this study, infarct size was used as the end point of injury because this measure is a robust indicator of preconditioning-induced cardioprotection.

\section{Materials and Methods}

Animals

A total of 77 male Sprague-Dawley rats (200-250 g) were used. Animals were kept in the normal animal room under standard laboratory conditions. All experiments were conducted in accordance with the institutional guidelines of Tehran University of Medical Sciences (Tehran, Iran) and the National Institutes of Health guidelines for the care and use of laboratory animals. The animals were randomly assigned to 11 treatment groups $(\mathrm{n}=7)$ and anesthetized by pentobarbital sodium (60 mg/kg b.w., intraperitonally).

\section{Chemicals}

Diazoxide, glibenclamid, $\mathrm{MgSO}_{4}$ and TTC were obtained from Sigma-Aldrich (Deisinhofen, Germany) and general laboratory chemicals were purchased from Merck (Darmstadt, Germany). Stock solutions of diazoxide and glibenclamide were prepared separately and then diluted to appropriate concentrations in KrebsHenseleit bicarbonate (KHB) buffer and equilibrated with $95 \% \mathrm{O}_{2}-5 \% \mathrm{CO}_{2}\left(\mathrm{pH} 7.4\right.$ at $\left.37^{\circ} \mathrm{C}\right)$.

\section{Isolated heart perfusion}

Rats were anesthetized with pentobarbital sodium (60 mg/kg, ip) $30 \mathrm{~min}$ after treatment with heparin sodium (500 IU). Hearts were cannulated in situ after the induction of anesthesia and mounted on a nonrecirculating, constant-pressure (80-100 $\mathrm{mm} \mathrm{Hg}$ ) Langendorff perfusion system and were perfused with an oxygenated $\left(95 \% \mathrm{O}_{2}-5 \% \mathrm{CO}_{2}\right)$ normothermic $\left(37^{\circ} \mathrm{C}\right)$ KHB buffer which had the following composition (in mmol/1): $\mathrm{NaHCO}_{3} 25 ; \mathrm{KCl} 4.7 ; \mathrm{NaCl} 118.5 ; \mathrm{MgSO}_{4}$ 1.2; $\mathrm{KH}_{2} \mathrm{PO}_{4}$ 1.2, glucose 11, $\mathrm{CaCl}_{2} 2.5$ (pH 7.4). The perfusion apparatus was water-jacketed to maintain a constant perfusion temperature of $37^{\circ} \mathrm{C}$ and during prolonged global ischemic periods hearts were immersed in $\mathrm{KHB}$ buffer at $37{ }^{\circ} \mathrm{C}$. Hearts were allowed to beat spontaneously throughout the experiments. A latex, fluidfilled, isovolumic balloon was introduced into the left ventricle through the left atrial appendage and inflated to give a preload of 8 to $10 \mathrm{~mm} \mathrm{Hg}$ and connected to a pressure transducer (Harvard).

Hemodynamic data was monitored with a homemade program (Ossilo Graph Monitor, Medicore). Left ventricular developed pressure, heart rate, and coronary flow were registered at regular intervals. Ischemia was achieved by clamping the aortic perfusion 
catheter in such a way that coronary flow was reduced to zero.

The rats were assigned into 11 experimental groups as: 1) controls (Con): hearts were perfused for 160 min; 2) ischemia-reperfusion (IR): in this group $30 \mathrm{~min}$ of stabilization were followed by 30 mins of global ischemia and $90 \mathrm{~min}$ reperfusion; 3) ischemic preconditioning (IPC): in this group, after stabilization, hearts were subjected to $5 \mathrm{~min}$ of ischemia and $5 \mathrm{mins}$ reperfusion before global ischemia; 4) magnesium preconditioned group (Mg-Pre): after a stabilization, hearts were perfused with $\mathrm{Mg}(8 \mathrm{mmol} / \mathrm{l})$ (Ebrahimi et al. 2004) for $5 \mathrm{~min}$ before global ischemia; 5) magnesium reperfused group (Mg-Rep): protocol for this group was as for the IR group except that hearts were perfused with $\mathrm{Mg}$ (8 $\mathrm{mmol} / \mathrm{l}$ ) during $90 \mathrm{~min}$ of reperfusion; 6) diazoxide-treated group (Dia): after stabilization, hearts were perfused with Dia $(30 \mu \mathrm{mol} / \mathrm{l})$ (Hicks et al. 1999) for $5 \mathrm{~min}$ before global ischemia; 7) glibenclamide-treated group (Gli): after stabilization, hearts were perfused with Gli $(10 \mu \mathrm{mol} / \mathrm{l})$ (Hicks et al. 1999) for $5 \mathrm{~min}$ before global ischemia; 8) magnesium preconditioned and diazoxide-treated group ( $\mathrm{Mg}$-Pre + Dia): after stabilization, hearts were perfused with $8 \mathrm{mmol} / \mathrm{l} \mathrm{Mg}+30 \mu \mathrm{mol} / \mathrm{l} \mathrm{Dia}$ for $5 \mathrm{~min}$ before global ischemia; 9) magnesium preconditioned and glibenclamide-treated group (Mg-Pre + Gli): after stabilization, hearts were perfused with $\mathrm{Mg}(8 \mathrm{mmol} / \mathrm{l})+$ Gli $(10 \mu \mathrm{mol} / \mathrm{l})$ for $5 \mathrm{~min}$ before global ischemia; 10) magnesium reperfused and diazoxide-treated group (Mg-Rep + Dia) was like Dia group, except that hearts were perfused with $\mathrm{Mg}(8 \mathrm{mmol} / \mathrm{l})$ during $90 \mathrm{~min}$ reperfusion, and 11) magnesium reperfused and glibenclamide-treated group (Mg-Rep + Gli), was like Gli group, except that hearts were perfused with $\mathrm{Mg}$ ( $8 \mathrm{mmol} / \mathrm{l}$ ) during $90 \mathrm{~min}$ reperfusion. Perfusions of drugs for $5 \mathrm{~min}$ in all experimental groups were started $10 \mathrm{~min}$ before global ischemia.

Hearts were perfused for $30 \mathrm{~min}$ to establish hemodynamic equilibrium. Equilibration was established when HR and LVDP were maintained at the same level for three continuous measurement periods timed $5 \mathrm{~min}$ apart. Baseline measurements were recorded at the end of this time.

Administration of drugs for $5 \mathrm{~min}$ were performed via the second arm of perfusate cannula which was connected to the main perfusion cannula and the experimental conditions were kept constant throughout the experiment.

\section{Infarct size measurement}

At the end of the reperfusion period, hearts were frozen and kept in a $-20{ }^{\circ} \mathrm{C}$ freezer to facilitate slicing of $2 \mathrm{~mm}$ transverse sections across the long axis. All hearts had approximately the same size $(1.2 \mathrm{~cm}$; atria and great vessels excluded). Slices were incubated in $1 \%$ TTC in a phosphate buffer $\left(\mathrm{pH} \mathrm{7.4)}\right.$ for $30 \mathrm{~min}$ at $37{ }^{\circ} \mathrm{C}$. After staining, slices were immersed in $10 \%$ formaline for 24 hours to enhance the contrast between stained and unstained tissues. Tissues that were stained brick red were taken as viable, whereas pale or white tissues were taken as necrotic. The areas of the left ventricle and infarcted tissues were measured by way of a planimetry from the scanned hearts by using Photoshop program. Volumes were obtained by multiplying the area by the thickness of the slices. Infarct size was expressed as a percentage of left ventricular volume for each heart.

\section{Statistical analyses}

A statistical analysis was performed using SPSS (version 11.5 for Windows, SPSS, Chicago, IL, USA). Data are expressed as the mean \pm S.E.M. To account for inter-animal variability, the functional indices were measured during treatment periods and at the end of 90 min reperfusion period and expressed as a percentage of the control value recorded for each heart before any test intervention was introduced. Groups were compared by one-way ANOVA. If a significant $F$-value was obtained, the Tukey test was used to identify individual group differences. Differences were considered statistically significant at $P<0.05$.

\section{Results}

Because heart rate $(\mathrm{HR})$ and left ventricular developed pressure (LVDP) may recover to different degrees, rate pressure product (RPP) was calculated by multiplying heart rate with LVDP and presented as reliable left ventricular function parameter for the isolated heart.

The infarct size was used as the end point of injury because this measure is a robust indicator of preconditioning-induced protection. The infarct sizes were determined by using computer-aided planimetry. RPP is expressed as a percentage of an individual baseline and infarct size is expressed as a percentage of left ventricular volume.

No differences were obtained between the experimental groups for RPP at the end of $30 \mathrm{~min}$ of 
Table 1. Baseline hemodynamic characteristics.

\begin{tabular}{lcccc}
\hline Group & $\mathbf{n}$ & LVDP $(\mathbf{m m} \mathbf{H g})$ & $\mathbf{C F}(\mathbf{m l} / \mathbf{m i n})$ & HR (bpm) \\
\hline Con & 7 & $105.28 \pm 4.43$ & $10.2 \pm 1.20$ & $220 \pm 12$ \\
IR & 7 & $110.42 \pm 2.32$ & $10.15 \pm 1.71$ & $198 \pm 16$ \\
IPC & 7 & $108.17 \pm 4.48$ & $11.02 \pm 0.98$ & $203 \pm 15$ \\
Dia & 7 & $111.56 \pm 3.42$ & $10.76 \pm 1.5$ & $230 \pm 14$ \\
Gli & 7 & $112.32 \pm 3.10$ & $10.54 \pm 1.48$ & $223 \pm 13$ \\
Mg-Pre & 7 & $107.58 \pm 3.76$ & $11.08 \pm 1.1$ & $216 \pm 10$ \\
Mg-Pre + Dia & 7 & $109.52 \pm 3.48$ & $12.08 \pm 1.3$ & $210 \pm 16$ \\
Mg-Pre + Gli & 7 & $108.36 \pm 5.88$ & $10.89 \pm 1.02$ & $227 \pm 10$ \\
Mg-Rep & 7 & $107.32 \pm 6.05$ & $10.11 \pm 2.02$ & $213 \pm 12$ \\
Mg-Rep + Dia & 7 & $110.54 \pm 5.28$ & $11.00 \pm 3.05$ & $209 \pm 21$ \\
Mg-Rep + Gli & 7 & $105.09 \pm 4.32$ & $10.01 \pm 1.19$ & $221 \pm 17$ \\
\hline
\end{tabular}

Values are mean \pm S.E.M. $n$, number of hearts in each group; LVDP, left ventricular developed pressure; CF, coronary flow; HR, heart rate; Con, control; IR, ischemia-reperfusion; IPC, ischemic preconditioning; Dia, diazoxide; Gli, glibenclamide; Mg, magnesium; Pre, preconditioning; Rep, reperfusion.

adaptation before starting treatments and global ischemia (Table 1). During $30 \mathrm{~min}$ of global ischemia there was a reduction in RPP to zero which started to recover gradually by continuation of the reperfusion.

Diazoxide $(30 \mu \mathrm{mol} / \mathrm{l})$, as a mitochondrial $\mathrm{K}_{\mathrm{ATP}}$ channel opener, increased the recovery of the RPP in Dia group (69\% basal value) compared with the IR group ( $38 \%$ basal value, $\mathrm{P}<0.05$ ), and significantly decreased infarct size in Dia group $(10.2 \pm 1.27 \%)$ compared with IR group $(44.47 \pm 3.14 \%, \mathrm{P}<0.001)$. There was no significant difference in the Dia group compared with the control group for RPP (90\% basal value) and infarct size $(1.0 \pm 0.03 \%)$.

In the IPC and Mg-Pre groups, RPP ultimately recovered to $80 \%$ and $77 \%$ basal value vs IR group $(\mathrm{P}<0.001)$ at the end of $90 \mathrm{~min}$ reperfusion.

The protection was associated with magnesium in Mg-Pre $(9.79 \pm 0.76 \%)$ and with ischemia in IPC (8.69 $\pm 1.28 \%$ ) groups in decreasing infarct size compared with IR group $(\mathrm{P}<0.001)$. There were no significant differences in the RPP and infarct size in both IPC and Mg-Pre groups compared with control and Dia groups. Thus using $\mathrm{Mg}$ before the ischemia showed the same protection as a mitochondrial $\mathrm{K}_{\mathrm{ATP}}$ channel opener (Diazoxide) and classical IPC.

The protection was associated with magnesium in Mg-Rep group in decreasing infarct size $(29.25 \pm 3.41 \%)$ which was significantly different from IR group $(\mathrm{P}<0.01)$. The infarct size and recovery of the RPP (58\% of basal value) in the Mg-Rep group were significantly different from the Mg-Pre group $(\mathrm{P}<0.05)$.

When $\mathrm{Mg}$ (both as Pre and Rep) was used with diazoxide, there were no significant differences in the recovery of RPP between Mg-Pre and $\mathrm{Mg}$-Pre + Dia (70\% of basal value) or between Mg-Rep and Mg-Rep + Dia (58\% of basal value) groups at the end of $90 \mathrm{~min}$ reperfusion and also co-administration of Dia with Mg-Pre (11.26 $\pm 1.4 \%)$ did not show any further protection in decreasing infarct size in comparison with Dia and Mg-Pre alone.

Consequently, they did not show any useful effect of using two protective agents simultaneously, which may be a signal that $\mathrm{Mg}$ may induce its protection via mitochondrial $\mathrm{K}_{\mathrm{ATP}}$ channels. However, the co-administration of Dia with Mg-Rep (20.08 $\pm 3 \%$ for $\mathrm{Mg}-\mathrm{Rep}+\mathrm{Dia})$ decreased infarct size in so that there was a significant difference from IR group $(\mathrm{P}<0.001)$.

Glibenclamide was not able to increase the recovery of the RPP (52\% of basal value) and to decrease the infarct size $(33.08 \pm 1.4 \%)$ in the Gli group. There were significant differences between the Gli and Control groups $(\mathrm{P}<0.001)$ in the recovery of RPP and infarct size.

When glibenclamide was used in combination with Mg-Pre (52\% of basal value for Mg-Pre + Gli), recovery of the RPP was significantly different from Mg-Pre $(\mathrm{P}<0.05)$ and the control group $(\mathrm{P}<0.001)$.

Glibenclamide also abolished the protective effect of Mg-Pre group (29.1 $\pm 2.17 \%$ in Mg-Pre + Gli vs. $9.76 \pm 0.76 \%$ in Mg-Pre, $\mathrm{P}<0.001)$ in decreasing infarct 

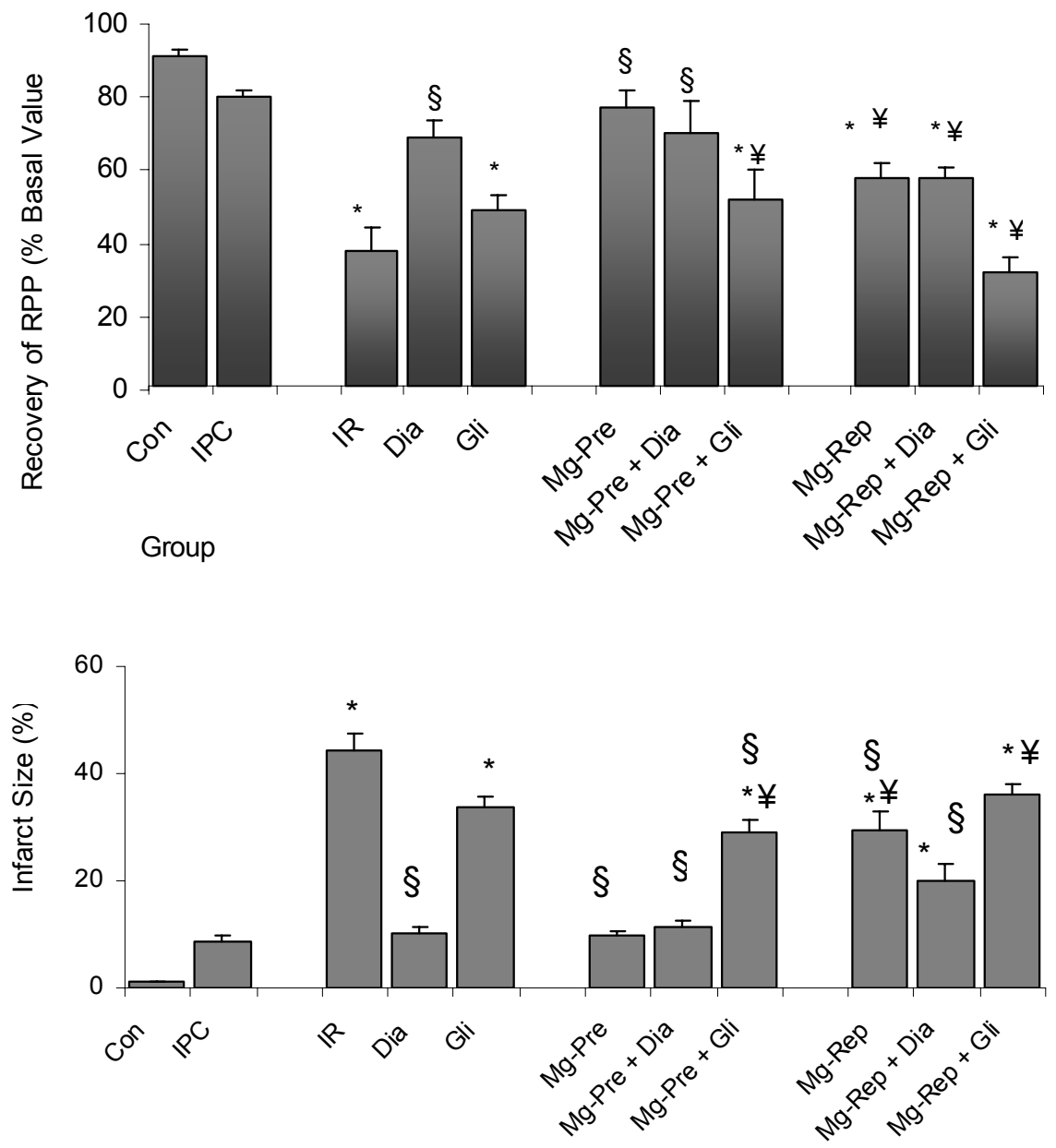

Group
Fig. 1. Recovery of RPP (Basal Value \%) in Con, IPC, IR, Dia, Gli, Mg-Pre, with Dia and Gli, and Mg-Rep, with Dia and Gli, groups. $(n=7)$, data are presented as Mean \pm S.E.M. Con, control; IR, ischemia- reperfusion; IPC, ischemic preconditioning; Dia, diazoxide; Gli, glibenclamide; Mg, magnesium; Pre, preconditioning; Rep, reperfusion. * Significant difference with Con group $(P<0.001)$. § Significant difference with IR group $(P<0.05)$. $¥$ Significant difference with $\mathrm{Mg}$-Pre group $(\mathrm{P}<0.05)$. size, whereas it had no effect on the Mg-Rep group (Figs 1 and 2).

Glibenclamide abolished Mg-Pre induced protection in recovery of the RPP and decreasing of infarct size, which suggests the role of $\mathrm{K}_{\mathrm{ATP}}$ channels in this protection.

\section{Discussion}

Ischemic preconditioning (IPC) is still a laboratory-based phenomenon that has not been documented conclusively in patients (Robert and Engler 1996). Although there is no drug known that completely prevents myocyte necrosis, some agents can slow the rate of cell death. The administration of $\mathrm{Mg}$ has been reported to protect the myocardium against ischemia and reduce reperfusion injury (Naik et al. 1999). It has been reported that $\mathrm{Mg}$ therapy starting early after reperfusion is effective in reducing infarct size in a swine model (Jynge and Falk 1995). In contrast, Mg therapy reduced infarct size when it was administered before, but not after, reperfusion in a rat model (Maulik et al. 1999). Although many studies have shown the involvement of $\mathrm{Mg}$ in cardioprotection by enhancing post-ischemic functional recovery and/or myocardial infarct size, there is some controversy regarding the results of these studies (Sameshima et al. 1998, Maulik et al. 1999, Abbott et al. 2003, Shirey 2004, Ueshima 2005). In fact, some clinical studies have shown that chronic supplementation of oral $\mathrm{Mg}$ is well tolerated and could improve endothelial function in symptomatic heart failure patients and is a preventive element in atherosclerosis and ischemic heart disease. Al-Delaimy et al. (2004) suggest that the intake of magnesium may lower the risk of congestive heart disease (Ueshima 2005, Fuentes et al. 2006).

Strong evidence has supported the role of $\mathrm{K}_{\mathrm{ATP}}$ channels as a mediator in IPC-induced cardio-protection against ischemia-reperfusion injury (Arena and Kass 1989, Wilde et al. 1989). Similarly, many studies have demonstrated that opening of $K_{\text {ATP }}$ channels by pharmacological tools such as diazoxide, a selective mitochondrial $\mathrm{K}_{\mathrm{ATP}}$ channels opener in cardiac myocyte, reduces myocardial injury, while blockade of these channels by some agents like glibenclamide eliminates 
the protection resulting from diazoxide and IPC (Hamada et al. 1990, Wilde et al. 1990). It is generally accepted that the mitochondrial $\mathrm{K}_{\mathrm{ATP}}$ is intimately involved in the cardioprotection induced by IPC. Garlid et al. (1997) provided the first direct evidence to support the role of mitochondrial $\mathrm{K}_{\mathrm{ATP}}$ channels in cardioprotection. They found that the cardioprotective effect of diazoxide was abolished by the $\mathrm{K}_{\mathrm{ATP}}$ channel antagonist 5-HD and glibenclamide, suggesting that mitochondrial $\mathrm{K}_{\mathrm{ATP}}$ channels were responsible for this action (Garlid et al. 1997). The sacolemmal $K_{\text {ATP }}$ channels may indeed act as a trigger for the opening of the mitochondrial $\mathrm{K}_{\mathrm{ATP}}$, or confer its own cardioprotection via a protein kinase Cdependent mechanism, which ultimately leads to a reduction in $\mathrm{Ca}$ overload during ischemia. Moreover, kir6.2-deficient mice are insensitive to IPC. Thus it appears that both sarcolemmal and mitochondrial $\mathrm{K}_{\mathrm{ATP}}$ channels have complementary roles in the cardioprotection afforded by IPC; indeed they may act in concert (Peart and Gross 2002).

In the present study, we assessed the preconditioning effect of $\mathrm{Mg}$ in the protection of the heart with respect to both post-ischemic functional recovery and infarct size in comparison with the effect of $\mathrm{Mg}$ which was used during reperfusion time.

So far $\mathrm{Mg}$ has not been used as a preconditioning agent in isolated rat heart and only one study from our lab has demonstrated its protective effect when it was used as bolus injection (Ebrahimi et al. 2004). $\mathrm{Mg}$ was perfused $10 \mathrm{~min}$ before global ischemia for $5 \mathrm{~min}$. The recovery of post-ischemic hemodynamic functions and the reduction of infarct size induced by $\mathrm{Mg}$ were significant and similar to those of IPC. When $\mathrm{Mg}$ was used after ischemia, it was not able to improve cardiac function, but decreased infarct size which was different from the control and IPC (Figs 1 and 2).

Experiments in animal models of myocardial infarction have provided the evidence that early $\mathrm{Mg}$ overload during or after ischemia (Ichikawa 1998) and adversely affect of mitochondria to generate ATP, which may be partly mediated by an increase in calcium overload in cytosol and/or mitochondria, leading to necrotic or apoptotic cell death in the ischemia-reperfused heart (Millane et al. 1994).

In this study it was clear that mitochondrial $\mathrm{K}_{\mathrm{ATP}}$ channels play a role in the protection afforded by $\mathrm{Mg}$ used before ischemia. Matsusaka and Jin (2002) were the first to report on the mechanism of the infarct sizelimiting effect of $\mathrm{Mg}$ in acute myocardial infarction.
Recently, it was reported that matrix $\mathrm{Mg}$ regulates mitochondrial $\mathrm{K}_{\mathrm{ATP}}$ channels in myocardium (Bednarczyk et al. 2005). In order to determine whether preconditioning effect of $\mathrm{Mg}$ is mediated via these channels, $\mathrm{Mg}$ was tested in the presence of a $\mathrm{K}_{\mathrm{ATP}}$ channel opener, diazoxide, and a potassium channel blocker, glibenclamide. Our results demonstrated that administration of glibenclamide abolished the protective effect of Mg.

Therefore mitochondrial $\mathrm{K}_{\text {ATP }}$ channels may be the target for the preconditioning effect of magnesium. Elam and Lansman (1995) also demonstrated that Mg has been a contributing factor in the gating of $\mathrm{K}^{+}$channels and binds to the closed channels during hyperpolarization and prevents its opening until it is occupied by potassium. We did not study any other possible mechanism for $\mathrm{Mg}$ preconditioning, but blockade of this effect by glibenclamide, a $\mathrm{K}_{\mathrm{ATP}}$ channels blocker, was clear in our experiment. In addition, the co-administration of diazoxide with magnesium in Mg-Pre + Dia group did not show any further protection in comparison with Dia and Mg-Pre groups, which may be a signal that $\mathrm{Mg}$ induces its protection almost exclusively via mitochondrial $\mathrm{K}_{\mathrm{ATP}}$ channels.

Diazoxide, $\mathrm{K}_{\mathrm{ATP}}$ channel opener, had the same cardioprotective effect as $\mathrm{Mg}$-Pre and classic ischemic preconditioning and the concentration of diazoxide ( $30 \mu \mathrm{mol} / \mathrm{l})$ is able to open mitochondrial subtype of $\mathrm{K}_{\mathrm{ATP}}$ channels only. Therefore the opening of mitochondrial $\mathrm{K}_{\mathrm{ATP}}$ channels is an important mechanism for induced cardioprotection when $\mathrm{Mg}$ is used as a pharmacological preconditioning agent (Garlid et al. 1997).

Continuous magnesium infusion effectively reduces the rate of arrhythmias following cardiopulmonary bypass surgery for congenital heart disease and causes quick recovery without increasing the incidence of dysrhythmia in pediatric patients, and should, therefore, be routinely used (Dittrich et al. 2003, Hoshino et al. 2003, Jian et al. 2003). Its antiarrhythmic effect may be related to its pharmacological properties but not to normalization of the circulating magnesium concentration (Kiziltepe et al. 2003).

Hhypomagnesemia appears to have an adverse pathophysiological effect and $\mathrm{Mg}$ deficit and other electrolyte abnormalities are frequent disorders in patients with congestive heart failure (Cohen et al. 2003). The therapeutic value of $\mathrm{Mg}$ in the management of coronary risk factors and ischemic heart disease has been clarified and the administration of magnesium can be 
considered as clinically valuable.

While the beneficial effects of $\mathrm{Mg}$ are apparent, further research is needed for the incorporation of these findings on the myocardial protective role of $\mathrm{Mg}$ in order to reduce morbidity and mortality of patients suffering from a variety of cardiac diseases.

\section{Conflict of Interest}

There is no conflict of interest.

\section{Acknowledgements}

We would like to acknowledge that Tehran University of Medical Sciences has financially supported this research.

\section{References}

ABBOTT RD, ANDO F, MASAKI KH, TUNG KH, RODRIGUEZ BL, PETROVITCH H, YANO K, CURB JD: Dietary magnesium intake and the future risk of coronary heart disease (the Honolulu Heart Program). Am J Cardiol 92: 665-669, 2003.

AL-DELAIMY WK, RIMM EB, WILLETT WC, STAMPFER MJ, HU FB: Magnesium intake and risk of coronary heart disease among men. J Am Coll Nutr 23: 63-70, 2004.

ARENA JP, KASS RS: Activation of ATP-sensitive K channels in heart cells by pinacidil: dependence on ATP. Am J Physiol 257: H2092-H2096, 1989.

BEDNARCZYK P, DOLOWY K, SZEWCZYK A: Matrix $\mathrm{Mg}^{2+}$ regulates mitochondrial ATP-dependent potassium channel from heart. FEBS Lett 579: 1625-1632, 2005.

CHAKRABORTI SCT, MANDAL M, MANDAL A, DAS S, GHOSH S: Protective role of magnesium in cardiovascular diseases. Mol Cell Biochem 238: 163-179, 2002.

COHEN N, ALMOZNINO-SARAFIAN D, ZAIDENSTEIN R, ALON I, GORELIK O, SHTEINSHNAIDER M, CHACHASHVILY S, AVERBUKH Z, GOLIK A, CHEN-LEVY Z, MODAI D: Serum magnesium aberrations in furosemide-treated patients with congestive heart failure: pathophysiological correlates and prognostic evaluation. Heart 89: 411-416, 2003.

DITTRICH S, GERMANAKIS J, DAHNERT I, STILLER B, DITTRICH H, VOGEL M, LANGE PE: Randomised trial on the influence of continuous magnesium infusion on arrhythmias following cardiopulmonary bypass surgery for congenital heart disease. Intensive Care Med 29: 1141-1144, 2003.

EBRAHIMI S, FAGHIHI M, KESHAVARZ M, KADKHODAEE M, MIRERSHADI F, ASADI B: Anti-infarct effect of magnesium is not mediated by adenosine $\mathrm{A}_{1}$ receptors in rat globally ischemic isolated hearts. Clin Exp Pharmacol Physiol 31: 868-872, 2004.

ELAM TR, LANSMAN JB: The role of $\mathrm{Mg} \mathrm{2+}$ in the inactivation of inwardly rectifying $\mathrm{K}+$ channels in aortic endothelial cells. J Gen Physiol 105: 463-484, 1995.

FOX ML, BURROWS FA, REID RW, HICKEY PR, LAUSSEN PC, HANSEN DD: The influence of cardiopulmonary bypass on ionized magnesium in neonates, infants, and children undergoing repair of congenital heart lesions. Anesth Analg 84: 497-500, 1997.

FUENTES JC, SALMON AA, SILVER MA: Acute and chronic oral magnesium supplementation: effects on endothelial function, exercise capacity, and quality of life in patients with symptomatic heart failure. Congest Heart Fail 12: 9-13, 2006.

GARLID KD, PAUCEK P, YAROV-YAROVOY V, MURRAY HN, DARBENZIO RB, D'ALONZO AJ, LODGE NJ, SMITH MA: Cardioprotective effect of diazoxide and its interaction with mitochondrial ATP-sensitive K cannels. Possible mechanism of cardioprotection. Cir Res 81: 1072-1082, 1997.

HAMADA E, TAKIKAWA R, ITO H, IGUCHI M, TERANO A, SUGIMOTO T, KURACHI Y: Glibenclamide specifically blocks ATP-sensitive $\mathrm{K}^{+}$channel current in atrial myocytes of guinea pig heart. Jpn J Pharmacol 54: 473-477, 1990.

HICKS M, DU ZY, JANSZ P, RAINER S, SPRATT P, MACDONALD PS: ATP-sensitive potassium channel activation mimics the protective effect of ischaemic preconditioning in the rat isolated working heart after prolonged hypothermic storage. Clin Exp Pharmacol Physiol 26: 20-25, 1999.

HOSHINO K, OGAWA K, HISHITANI T, KITAZAWA R: Influence of heart surgery on magnesium concentrations in pediatric patients. Pediatr Int 45: 39-44, 2003. 
ICHIKAWA S: Magnesium and calcium changes in serum and atrial muscle caused by open heart surgery and the effect of preoperative oral magnesium administration. Jpn J Thorac Cardiovasc Surg 46: 287-298, 1998.

JIAN W, SU L, YIWU L: The effects of magnesium prime solution on magnesium levels and potassium loss in open heart surgery. Anesth Analg 96: 1617-1620, 2003.

JYNGE P, FALCK G: High magnesium improves the postischemic recovery of cardiac function. Cardiovasc Res 29: 439, 1995.

KIZILTEPE U, EYILETEN ZB, SIRLAK M, TASOZ R, ARAL A, EREN N T, UYSALEL A, AKALIN H: Antiarrhythmic effect of magnesium sulfate after open heart surgery: effect of blood levels. Int J Cardiol 89: 153-158, 2003.

LI Y, DENG Q, FU Z: Effects of glibenclamide on mRNA level of ATP-sensitive potassium channels of heart in normal and streptozotocin-induced diabetic rats. Zhonghua Yi Xue Za Zhi 80: 538-540, 2000.

MAULIK M, MAULIK S K, KUMARI R: Importance of timing of magnesium administration: a study on the isolated ischemic-reperfused rat heart. Magnes Res 12: 37-42, 1999.

MILLANE T, WILSON AJ, PATEL MK, JENNISON SH, HOLT DW, MURDAY AJ, CAMM AJ: Mitochondrial calcium deposition in association with cyclosporine therapy and myocardial magnesium depletion: a serial histologic study in heart transplant recipients. J Heart Lung Transplant 13: 473-480, 1994.

MIURA T, MIKI T: ATP-sensitive $\mathrm{K}^{+}$channel openers: old drugs with new clinical benefits for the heart. Curr Vasc Pharmacol 1: 251-258, 2003.

MUTSUSAKA THN, JIN YT: Magnesium reduces myocardial infarct size via enhancement of adenosine mechanism in rabbits. Cardiovasc Res 54: 568-575, 2002.

NAIK P, MALATI T, RATNAKAR KS, NAIDU MU, RAJASEKHAR A: Cardioprotective effect of magnesium chloride in experimental acute myocardial infarction. Indian J Exp Biol 37: 131-137, 1999.

PEART JN, GROSS GJ: Sarcolemmal and mitochondrial K(ATP) channels and myocardial ischemic preconditioning. J Cell Mol Med 6: 453-464, 2002.

ROBERT L, ENGLER DMY: Sulfonylurea $\mathrm{K}_{\text {ATP }}$ blockade in type II diabetes and reconditioning in cardiovascular disease. Circulation 94: 2297-2301, 1996.

SAMESHIMA H, IKENOUE T, KAMITOMO M, SAKAMOTO H: Effects of 4 hours magnesium sulfate infusion on fetal heart rate variability and reactivity in a goat model. Am J Perinatol 15: 535-538, 1998.

SHECHTER M, MERZ CN, PAUL-LABRADOR M, MEISEL SR, RUDE RK, MOLLOY MD, DWYER JH, SHAH PK, KAUL S: Beneficial antithrombotic effects of the association of pharmacological oral magnesium therapy with aspirin in coronary heart disease patients. Magnes Res 13: 275-284, 2000.

SHIREY TL: Monitoring magnesium to guide magnesium therapy for heart surgery. $J$ Anesth 18: 118-128, 2004.

STUHLINGER SCT, MANDAL M, MANDAL A, DOS S, GHOSH S: Protective role of magnesium in cardiovascular disease. Mol Cell Biochem 238: 163-179, 2002.

UESHIMA K: Magnesium and ischemic heart disease: a review of epidemiological, experimental, and clinical evidences. Magnes Res 18: 275-284, 2005.

WILDE AA, ESCANDE D, SCHUMACHER CA, THURINGER D, MESTRE M, FIOLET JW: Glibenclamide inhibition of ATP-sensitive $\mathrm{K}^{+}$channels and ischemia-induced $\mathrm{K}^{+}$accumulation in the mammalian heart. Pflugers Arch 414: S176, 1989.

WILDE AA, ESCANDE D, SCHUMACHER CA, THURINGER D, MESTRE M, FIOLET JW, JANSE MJ: Potassium accumulation in the globally ischemic mammalian heart. A role for the ATP-sensitive potassium channel. Circ Res 67: 835-843, 1990.

YOKOYAMA AK, KAWAMURA Y: Heart rate variability, arrhythmia and magnesium in hemodialysis patients. Clin Calcium 15: 226-232, 2005. 